\title{
In Vitro Study Towards Role of Acrylamide-Induced Genotoxicity in Human Lymphocytes and the Protective Effect of L-Carnitine
}

\author{
Ehsan Zamani ${ }^{1,2}$, Mohammad Shokrzadeh ${ }^{3,4}$, Mona Modanloo', Fatemeh Shaki ${ }^{3,4 *}$ \\ ${ }^{1}$ Student Research committee, Mazandaran University of Medical Science, Sari, Iran. ${ }^{2}$ Department of Toxicology \\ and Pharmacology, Faculty of Pharmacy, Guilan University of Medical Science, Rasht, Iran. \\ ${ }^{3}$ Pharmaceutical Science Research center, Hemoglobinopathy Institute, Mazandaran University of Medical Science, \\ Sari, Iran. ${ }^{4}$ Department of Toxicology and Pharmacology, Faculty of Pharmacy, Mazandaran University of Medical \\ Science, Sari, Iran
}

\begin{abstract}
Acrylamide (AA), is an important industrial compound, formed during food processing under high temperature. Due to its potential carcinogenic effect, it has been recognized as a human health concern. In this study, we investigated the role of oxidative stress in acrylamide's genotoxicity and protective role of $L$ - carnitine (LCA) in human lymphocytes. The micronucleus test (MNT) was used to monitor AA genotoxicity after $20 \mathrm{~h}$ exposure to concentrations of 0.25,50 and $100 \mathrm{mM}$. Furthermore we evaluated oxidative stress markers, such as reactive oxygen species (ROS), lipid peroxidation (LPO) and glutathione (GSH) content. In MNT, It has been found that AA at high concentrations (50 and $100 \mu \mathrm{M}$ ) significantly increased the micronuclei $(M N)$ frequencies. On the one hand, AA exposure induced ROS formation, LPO and also GSH oxidation in treated lymphocytes. On the other hand, pretreatment with LCA $(100$ and $200 \mu M)$ inhibited AA-induced oxidative stress which subsequently led to decreasing of the micronuclei (MN) frequencies in human lymphocytes. In overall, the clastugenic effect of acrylamide was confirmed. Also, it has been observed that LCA prevented AA genotoxicity via amelioration of oxidative stress in human lymphocytes. Therefore, oxidative stress suggested as an important factor involved in acrylamide-induced genotoxicity.
\end{abstract}

Keywords: Acrylamide, L- carnitine, micronucleus, oxidative stress, genotoxicity

\footnotetext{
*Author of correspondence: fshaki.tox@gmail.com, fshakki@mazums.ac.ir
} 


\section{INTRODUCTION}

Acrylamide $(\mathrm{CH} 2=\mathrm{CH}-\mathrm{CO}-\mathrm{NH} 2 ; 2$-propenamide $)$ is a white crystalline vinylic compound with a molecular weight of $71.08 \mathrm{kDa}^{(1)}$.It is a colorless, odorless solid that is formed during food processing under high temperature via the Maillard reaction, especially during the processing of food containing asparagines and glucose ${ }^{(2)}$. Processed potato products, bread, breakfast cereals, biscuits, cookies, snacks, and coffee have been found to contain different levels of acrylamide residues ${ }^{(3)}$.Also, it has been used in the industry, especially in the form of polyacrylamides utilized in adhesives and grouts, soil stabilizers and in laboratory gels since $1950^{(4,5)}$. In the environment, acrylamide (AA) has a high mobility in soil and in ground water. Therefore, AA can be considered as an environmental and occupational pollutions ${ }^{(6,7)}$. Investigations of AA toxicity have focused primarily on its neurotoxicity ever since this effect was first observed in laboratory animals and industrial workers over 30 years ago $^{(4)}$.In 1994, the International Agency for Research on Cancer (IARC 1994) classified AA as "potentially carcinogenic to humans"(8), and in 2001, the Scientific Committee on Toxicity, Ecotoxicity and the Environment firmly demonstrated its toxic properties including neurotoxicity, genotoxicity to the both somatic and germ cells, carcinogenicity and reproductive toxicity ${ }^{(9)}$.

In addition, EU Risk Assessment Report indicated that acrylamide was carcinogenic in animals and increased incidences of a number of benign and malignant tumors in a variety of organs (e.g. thyroid, adrenals and testicular mesothelioma) ${ }^{(10)}$.

Besides, physical, chemical and biological agents can act in the DNA, resulting in genotoxicity which involves in carcinogenicity ${ }^{(11)}$. Genotoxicity can be also considered as one of causes of acrylamide's carcinogenicity. IARC reported that AA induces gene mutation, structural chromosomal aberrations, sister chromatid exchange and mitotic disturbances in mammalian cells. AA and its metabolite glycidamide can make covalent adducts with DNA and create genotoxicity ${ }^{(4)}$.

Several studies revealed the role of oxidative stress in the pathogenesis of AA toxicity (12-14). Moreover, Induction of genotoxicity via oxidative damage to the DNA by oxidant compounds have been shown in several studies ${ }^{(15-17)}$.Oxidative stress defined as an imbalance in the biological oxidant-to-antioxidant ratio. Oxidative stress results from excess reactive oxygen species (ROS), especially due to the exposure to environmental pollution ${ }^{(18)}$. ROS can attack to cellular macromolecules, including lipids, proteins, and DNA and induce cellular damage ${ }^{(19)}$.

There has been several studies that showed antioxidant compounds can inhibit DNA oxidative damage and genotoxicity ${ }^{(20-22)}$. For example, yang et al showed that antioxidant such as, zinc could prevent aflatoxin-induced cytotoxicity and genotoxicity, induced in rats via attenuation of oxidative stress pathway ${ }^{(11)}$.

$\mathrm{L}$ carnitine (LCA) is a compound that shows antioxidant effects. Regarding the antioxidant capacity of LCA, human and animal data support the notion that LCA treatment exerts beneficial effects in several disorders that are related to oxidative stress.

In this study we evaluated the role of Acrylamide induced oxidative stress in its genotoxicity in human lymphocytes. Also, the protective effect of LCA against Acrylamide -induced oxidative stress and subsequently its genotoxicity was investigated ${ }^{(23)}$. 


\section{METHODS}

\section{Sample Preparation}

The study was carried out by using blood sample from healthy, young (20-24 years) male. The criteria of acceptability to ensure reliability of the experiment were: having good health, without serious illness and receiving any medical therapy, from nonalcoholic non-smoker person ${ }^{(24)}$.

\section{Micronucleus Test}

The Micronucleus test (MNT) in human lymphocytes can be performed using whole blood cultures. The MNT was conducted according to the method of Fenech et al. ${ }^{(25)}$. Briefly, $0.5 \mathrm{ml}$ of whole blood was mixed with $4.5 \mathrm{ml}$ of RPMI-1640 medium supplemented with $20 \%$ fetal calf serum, $100 \mathrm{U} / \mathrm{ml}$ penicillin and $100 \mathrm{mg} / \mathrm{ml}$ streptomycin. $0.2 \mathrm{mg} / \mathrm{ml}$ phytohaemagglutinin-M (PHA) was added to stimulate the culture. Cultures were incubated in duplicates at $37^{\circ} \mathrm{C}$ for $72 \mathrm{~h}$. At the $24 \mathrm{~h}$ of the first day, cells treated as follows: control, AA $(10,25,50$ and $100 \mathrm{mM}), \mathrm{AA}(50 \mathrm{mM})$ that pretreated with LCA (100 and $200 \mathrm{mM}$ ). After $20 \mathrm{~h}$ exposure, Cytochalasin-B (5 $\mathrm{mg} / \mathrm{ml}$ ) was added to arrest the cells atcytokinesis ${ }^{(26)}$.

The cultures were harvested by centrifugation after $28 \mathrm{~h}$. The lymphocytes were subjected to mild hypotonic treatment with $0.075 \mathrm{M} \mathrm{KCl}$ for $5 \mathrm{~min}$, then fixed in fresh fixative solution (3:1, methanol: acetic acid). This fixation was repeated twice. Few drops of cell suspension was smeared on pre-cooled microscopic slides and air-dried. The slides were stained using $10 \%$ giemsa of $\mathrm{pH} 6.8$ for $10 \mathrm{~min}$. around one thousand binucleated lymphocytes per culture were scored at 400X magnification. Frequency of micronuclei (MN) and nucleoplasmic bridges per 1000 cells was calculated and reported as percentage ${ }^{(26)}$.

\section{Measurement of Reactive Oxygen Species}

The intracellular reactive oxygen species (ROS) production was measured using dichloro- di hydro-fluorescein diacetate (DCFH-DA) by method developed by Halliwell and Whiteman, with some modification ${ }^{(27)}$. DCFH-DA breached the cells and was hydrolyzed by intracellular esterase to the nonfluorescent DCFH, which could be rapidly oxidized to the highly fluorescent 2,7-dichlorofluorescein (DCF) in the presence of $\operatorname{ROS}^{(28)} .2 \mathrm{ml}$ medium contained lymphocytes $\left(1 \times 10^{6}\right.$ cells) from treatment group were washed twice with cold PBS and then suspended in PBS, and incubated with DCFH-DA at a final concentration of $10 \mu \mathrm{M}$ for an additional $20 \mathrm{~min}$ at $37^{\circ} \mathrm{C}$ in the dark. The fluorescent intensity of the cell suspensions was measured with a Shimadzu RF5000U fluorescence spectrophotometer Excitation and emission wavelengths were 500 and $520 \mathrm{~nm}$, respectively ${ }^{(29)}$. The results were expressed as fluorescent intensity per $10^{6}$ cells.

\section{Measurement of Lipid Peroxidation}

The content of malondialdehyde (MDA) was determined by the thiobarbituric acid (TBA) reactive substances introduced as the amount of MDA produced, during an acid-heating reaction. Briefly, $0.25 \mathrm{ml}$ sulfuric acid $(0.05 \mathrm{M})$ was added to $10^{6}$ lymphocytes (from every groups)., with later addition of $0.3 \mathrm{ml} 0.2 \%$ TBA. All the micro tubes were placed in a boiling water bath for $30 \mathrm{~min}$. At the end, the tubes were shifted to an ice-bath, while $0.4 \mathrm{ml} \mathrm{n}$-butanol was added to each tube. Then, they were centrifuged at $\times 3500 \mathrm{~g}$ for $10 \mathrm{~min}$. The amount of MDA formed in each sample was assessed by measuring the absorbance of the supernatant at $532 \mathrm{~nm}$ with an ELISA reader (Tecan, Rainbow Thermo and Austria). Tetramethoxypropane was used as a standard and MDA content was expressed as $\mathrm{nmol} / \mathrm{mg}$ protein $^{(29)}$. 


\section{Measurement of Glutathione Content}

Glutathione (GSH) content was evaluated using 5, 5'-dithiobis-2-nitrobenzoic acid (DTNB) as the indicator and spectrophotometer method for treated lymphocytes. Before the addition the Cytochalasin-B, $10^{6}$ Lymphocytes, which was treated with AA $(50 \mathrm{mM})$ and AA + LCA (100 and $200 \mu \mathrm{M})$, selected and added into $0.1 \mathrm{~mol} / \mathrm{l}$ of phosphate buffers and $0.04 \%$ DTNB in a total volume of $3.0 \mathrm{ml}(\mathrm{pH} \mathrm{7.4)}$. The produced yellow color was read at $412 \mathrm{~nm}$ on a spectrophotometer (UV-1601 PC, Shimadzu, Japan). GSH content was observed as $\mu \mathrm{M}^{(29)}$.

\section{Statistical Analysis}

Results are presented as mean \pm standard error. All statistical analyses were performed using the SPSS software, (version10). Assays were performed in triplicate, and the mean was used for statistical analysis. Statistical significance was determined using the one-way ANOVA test, followed by the post-hoc Tukey test. Statistical significance was set at $P<0.05$.

\section{RESULTS}

\section{Micronucleus Test}

MNT was performed in the current study to investigate whether AA was genotoxic to lymphocytes or not. Cytogenetic damage measured as frequency of $\mathrm{MN}$ in binucleated lymphocytes (Figure 1). Frequency of $\mathrm{MN}$ after treatment of lymphocyte with different concentration of $\mathrm{AA}(5,25,50$ and $100 \mathrm{mM})$ was measured. As shown in Figure 2, the significant increase in frequency of $\mathrm{MN}$ was observed at concentration of 50 and $100 \mathrm{mM}(P<0.05)$. Also, pre-treatment with LCA significantly protected against AA-induced genotoxicity in lymphocytes (Figure $2 \mathrm{~B}$ ).
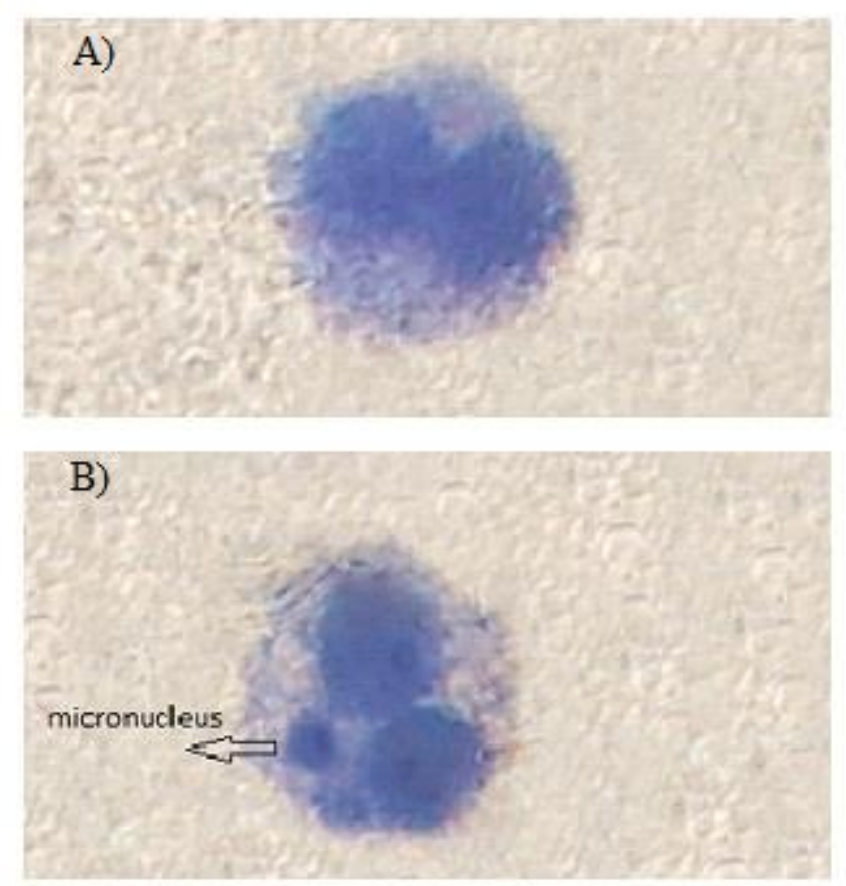

Figure 1. Geimsa stained binucleated cell in human lymphocytes: A) control (without the micronucleus), B) AA treated (with the micronucleus) 
A)

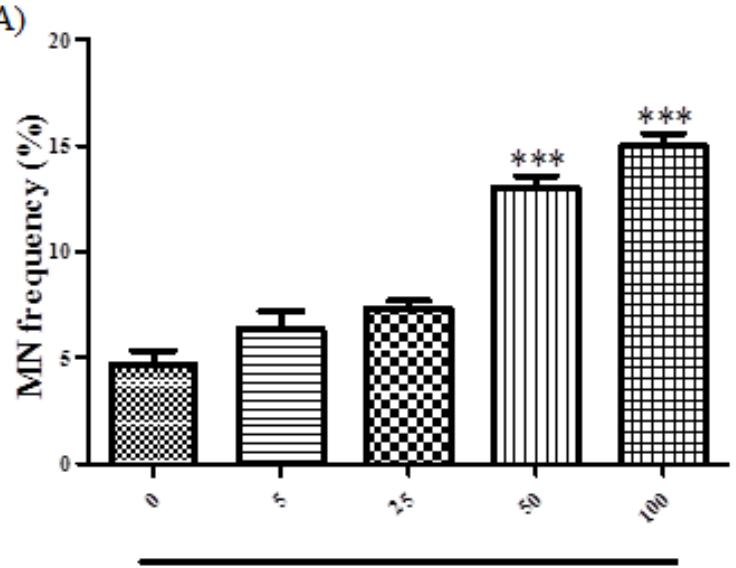

Acrylamide (mM)
B)

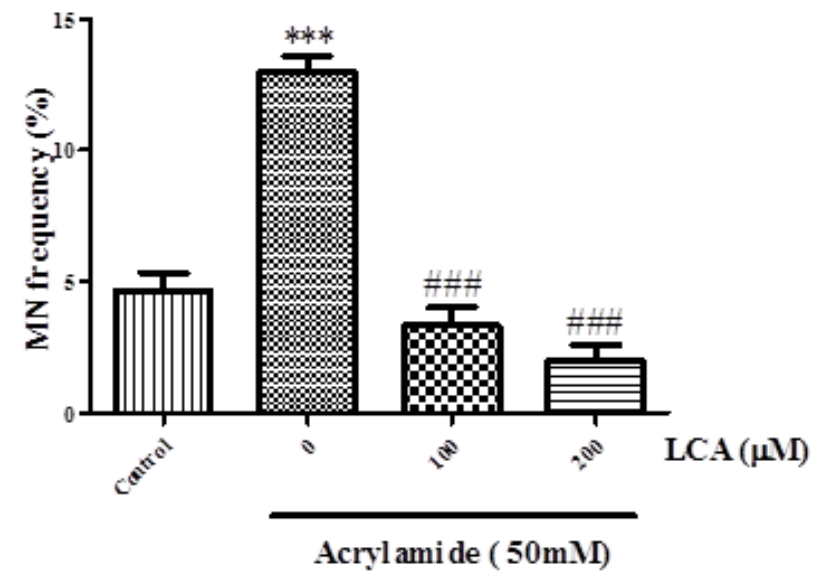

Figure 2. Frequency of micronuclei (MN) in human lymphocytes. A) Concentration-effect of Acrylamide (AA) on frequency of MN. B) Effect of L-carnitine (LCA) on AA-induced genotoxicity. Values represent as Mean \pm SEM, *** $\mathrm{P}<0.001$ compared with control group, \#\#\# $\mathrm{P}<0.001$ compared with AA 50

\section{Reactive Oxygen Species}

The concentration of intracellular ROS was evaluated by the changes in DCF fluorescence intensity. As illustrated in Figure 3, ROS formation significantly enhanced by AA $(50 \mathrm{mM})$ than control group $(P<0.05)$.In the other hand, LCA significantly reduced AA-induced ROS production compared to AA-treated group $(P<0.05)$.

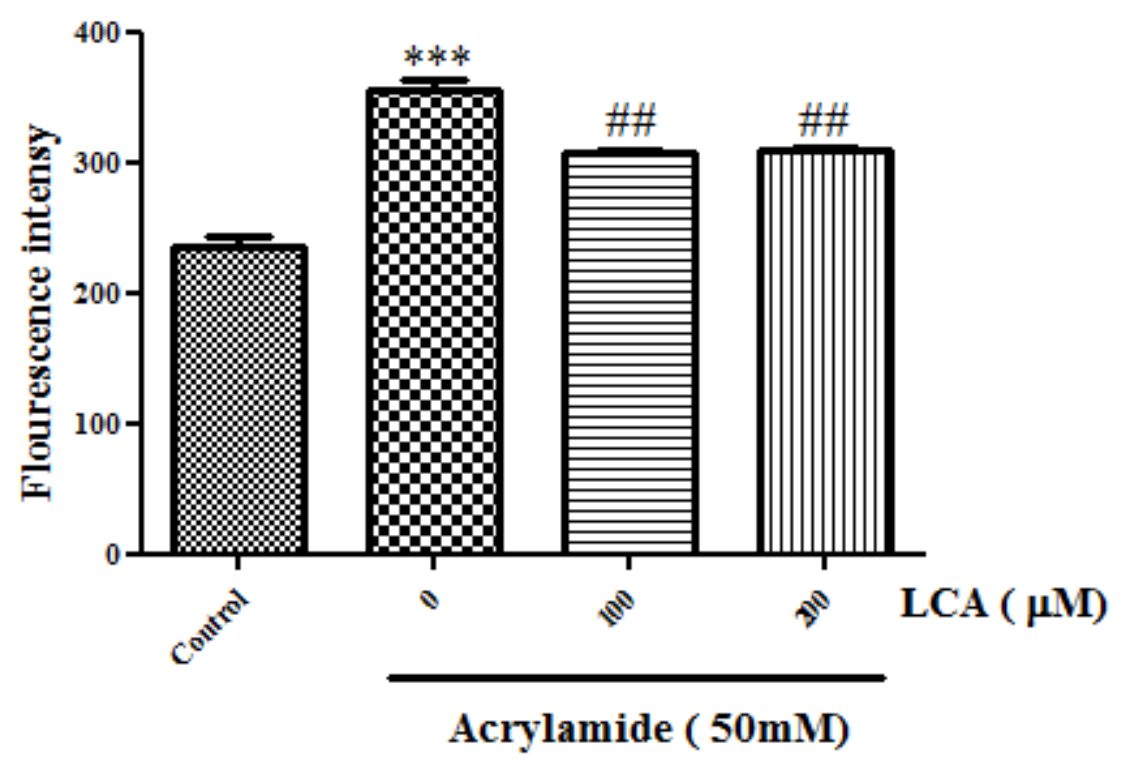

Figure 3. Protective effect of LCA against AA-induced intracellular ROS generation. Values represent as Mean \pm SEM, *** $\mathrm{P}<0.001$ compared with control group, \#\# $\mathrm{P}<0.01$ compared with AA 50

\section{Lipid Peroxidation}

Lipid peroxidation (LP) was the result of oxidative stress and evaluation of MDA (a final product of LP) that was used for assessment of oxidative stress. As shown in Figure 4, AA (50mM) significantly increased MDA concentration compared to control group $(P<0.05)$. Whereas pretreatment with LCA $(100$ and $200 \mu \mathrm{M})$, inhibited LP in lymphocytes as the concentration-depended manner $(P<0.05)$. 


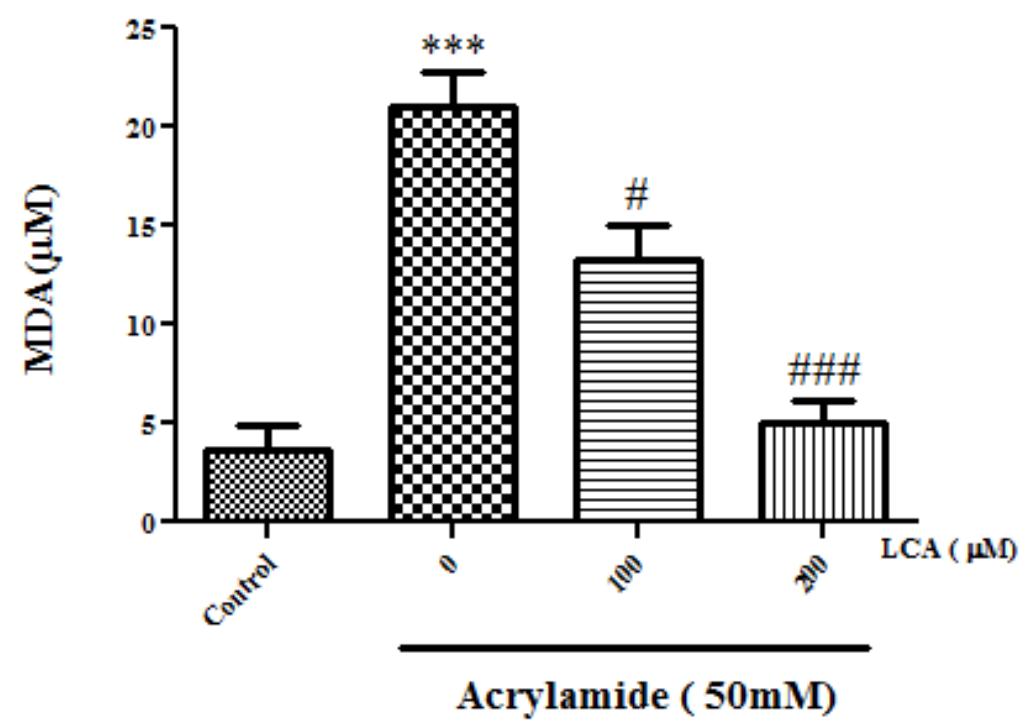

Figure 4. Protective effect of LCA against AA-induced lipid peroxidation. Values represent as Mean \pm SEM, *** $\mathrm{P}<0.001$ compared with control group, \# $\mathrm{P}<0.05$ compared with AA 50, \#\#\# $\mathrm{P}<0.001$ compared with AA 50

\section{Glutathione Content}

The GSH was an utmost antioxidant defense agent against free radicals. GSH could directly react with ROS in non-enzymatic reaction and oxidized to Glutathione disulfide (GSSG) ${ }^{(28)}$.

The GSH concentration in samples were evaluated to determine the extent of oxidative stress induced by AA. Exposures to AA $(50, \mathrm{mM})$ led to decrease in GSH levels to $86.75 \pm 7.22(\mathrm{nM})$, as compared to $149.25 \pm 7.22(\mathrm{nM})$ in the control group (Figure 5). Whereas, LCA treatment inhibited AA-induced GSH oxidation in lymphocytes that showed significant effect at concentration of $100 \mathrm{mM}(P<0.05)$.

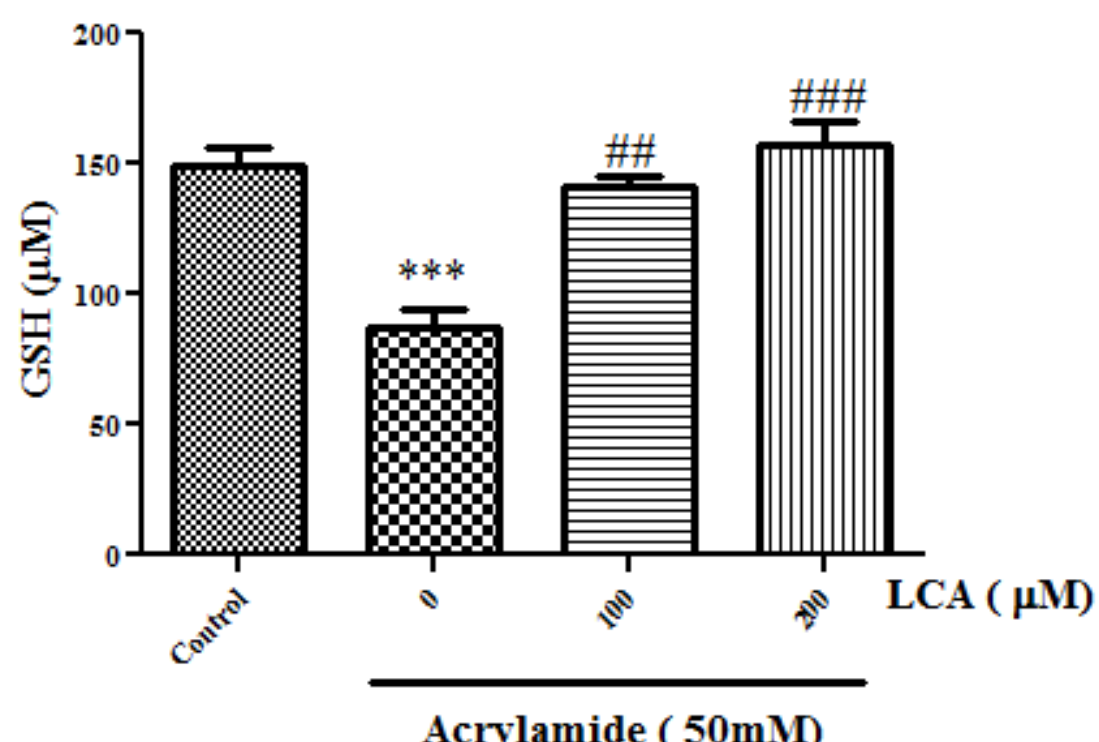

Figure 5. Protective effect of LCA against AA-induced GSH depletion. Values represent as Mean \pm SEM, *** $\mathrm{P}<0.001$ compared with control group, $* * \mathrm{P}<0.01$ compared with control group, \#\#\# $\mathrm{P}<0.001$ compared with AA 50 


\section{DISCUSSION}

Acrylamide (AA) is found in many high carbohydrates foods prepared at high temperatures $\left(>120^{\circ} \mathrm{C}\right)^{(30)}$. Recently, it has been gained attention because of adverse effects of dietary intake of AA for human and animals ${ }^{(6,31)}$.Genotoxicity is an important toxic effect of AA reported in many in vivo and in vitro studies $(4,28,32)$. Various in vivo genotoxicity tests demonstrated that AA could develop the genotoxicity properties like induction of aberrations and micronuclei in blood cells such as, peripheral RBC and spleen lymphocytes ${ }^{(33)}$, transgenic gene mutation in liver, and DNA damage in Comet assay in various organs ${ }^{(34-37)}$. Genotoxic effects include deletions, breaks and/or rearrangements can increase risk of cancer if the DNA damage does not immediately repair or promote into the cell death. DNA damage can be induced by a wide range of biological and chemical agent. The IARC based on finding of rodent carcinogenicity introduced AA as a probable human carcinogen (2A category) ${ }^{(8)}$. Furthermore, previous studies showed that AA initiated tumors in numerous organs including mammary gland, peritesticular mesothelium, thyroid, and central nervous system, even though the genotoxicity of AA in all of these organs have not been demonstrated. ${ }^{(38)}$. In contrast, AA has revealed negative results in bacterial gene mutation assays and comet assay even at high concentrations ${ }^{(35)}$. While, AA showed chromosome aberration and sister chromatid exchange in couple of tests like, MNT assay. These results proposed that AA was clastogenic without directly damaging DNA ${ }^{(35) \text {. }}$ However in the present study the higher concentrations of AA were significantly increased frequency of MN in the MNT assay (50 and $100 \mathrm{~m} \mathrm{M}$ ) $(P<0.05)$. While, in the other study by koyama et al, genotoxic effect of AA in MNT assay was observed in concentrations higher than $12.5 \mathrm{mM}^{(35)}$, which confirmed the clustogenic properties of AA.

Genotoxic compounds could induce DNA damage through mechanisms such as, oxidative stress or inflammatory procedures. Oxidative DNA damage can be induced by several pathways such as, chemical modification of nucleotides direct action of ROS on DNA, or indirectly via aldehydic lipid peroxidation degradation products ${ }^{(15)}$.

Recent studies reported the relation between AA-induced toxicity and cellular oxidative stress ${ }^{(39)}$. Many studies confirmed the ability of AA in production of ROS. ROS are very active free radicals that can attack to cellular macromolecules such as DNA. Free radicals can react with all segments of the DNA molecule (both the purine and pyrimidine bases and also the deoxyribose backbone). Genetic changes resulting from these ROS induced oxidative damage can play the first step involved in mutagenesis, carcinogenesis and ageing.

It is well established that free radical-mediated DNA damage occurred in various cancers. and the classifying of AA as a "potentially carcinogenic" compound to humans confirmed the ability of AA in inducing DNA damage.in other hand our studies showed AA ( in concentrations $\geq 50 \mathrm{mM}$ ) can promote frequency of $\mathrm{MN}^{(40)}$.

Also, ROS can attack to membrane lipids and induced lipid peroxidation. Lipid peroxidation is a destructive chain reaction which can lead to generation of more free radicals. Our results showed high concentration of $\mathrm{AA}(50 \mathrm{mM})$ increased lipid peroxidation in lymphocytes.

The harmful effects of ROS are detoxified by the antioxidant agents. Glutathione (GSH) is an important intrinsic antioxidant tripeptide capable of preventing harmful effect of ROS. In this procedure, glutathione oxidized to glutathione disulfide (GSSG). Our result showed high concentration of AA led to depletion of GSH level of lymphocytes ${ }^{(41)}$.

However AA decreased oxidative stress markers such as LP and GSH oxidation. In fact, a positive relation was found between rise of oxidative stress level and frequency of MN after the exposure. In the other hand, several researches revealed antioxidant 
protection against oxidant challenge might decrease the rate of mutation and genotoxicity; hence helped to prevent genotoxic-related disease including cancer ${ }^{(13,16}$, ${ }^{28,}{ }^{42}$. For confirmation the role of oxidative stress in AA genotoxicity, LCA, a wellknown antioxidant, was used for protection against AA genotoxicity.

1-Carnitine is a dietary supplement that plays an important role in passing of the longchain fatty acids across the inner mitochondrial membrane for $\beta$-oxidation and ATP production. 1-carnitine is a free radical scavenger, which shields antioxidant enzymes from oxidative damage then it prevents the accumulation of end-products of oxidative stress $^{(19,43)}$. Antioxidant properties of L-carnitine was shown in several experimental studies. For example in one study L- carnitine reduced lipid peroxidation in aging rats (44). In other studies, using of 1-carnitine improved oxidative damage induced by benzene in bone marrow cells ${ }^{(45)}$. Our results showed LCA treatment not only decreases the level of oxidative stress markers in lymphocyte exposed to AA, but also significantly inhibited the frequency of $\mathrm{MN}$ in these cells $(P<0.05)$. These data confirmed the role of oxidative stress in promotion of AA genotoxicity in human lymphocytes.

\section{CONCLUSION}

In overall, the clustogenic effect of AA in human lymphocytes was proven. In addition, oxidative stress was suggested as an important mechanism involved in genotoxicity effect of AA. Also, LCA showed beneficial effect for amelioration of AA induced genotoxicity through its anti-oxidative effects.

\section{CONFLICT OF INTEREST STATEMENT}

The authors have no conflict of interest related to this research to report.

\section{ACKNOWLEDGEMENT}

The data provided in this article was extracted from a project was supported by a grant from Mazandaran University of Medical Sciences (1822, 2015).

\section{REFERENCES}

1. Dearfield KL, Abernathy CO, Ottley MS, Brantner JH, Hayes PF. Acrylamide: its metabolism, developmental and reproductive effects, genotoxicity, and carcinogenicity. Mutation Research/Reviews in Genetic Toxicology. 1988;195[1]:45-77.

2. Mesías M, Morales FJ. Acrylamide in coffee: Estimation of exposure from vending machines. Journal of Food Composition and Analysis. 2016 5//;48:8-12.

3. Claus A, Carle R, Schieber A. Acrylamide in cereal products: A review. Journal of Cereal Science. 2008;47(2):118-33.

4. Blasiak J, Gloc E, Wozniak K, Czechowska A. Genotoxicity of acrylamide in human lymphocytes. Chemico-biological interactions. 2004;149(2):137-49.

5. Riboldi BP, Vinhas ÁM, Moreira JD. Risks of dietary acrylamide exposure: A systematic review. Food chemistry. 2014;157:310-22.

6. Exon J. A review of the toxicology of acrylamide. Journal of Toxicology and Environmental Health, Part B. 2006;9(5):397-412.

7. Croll BT, Arkell GM, Hodge RPJ. Residues of acrylamide in water. Water Research. 1974 1974/11/01;8(11):989-93. 
8. Mucci L, Dickman P, Steineck G, Adami H, Augustsson K. Dietary acrylamide and cancer of the large bowel, kidney, and bladder: absence of an association in a population-based study in Sweden. British Journal of Cancer. 2003;88[1]:84-9.

9. Keramat J, LeBail A, Prost C, Jafari M. Acrylamide in baking products: A review article. Food and Bioprocess Technology. 2011;4(4):530-43.

10. Rudén C. Acrylamide and cancer risk-expert risk assessments and the public debate. Food and Chemical Toxicology. 2004 3//;42(3):335-49.

11. Yang X, Lv Y, Huang K, Luo Y, Xu W. Zinc inhibits aflatoxin B1-induced cytotoxicity and genotoxicity in human hepatocytes (HepG2 cells). Food and Chemical Toxicology. 2016 6//;92:17-25.

12. Jin X, Coughlan M, Roberts J, Mehta R, Raju J. Dietary acrylamide exposure in male F344 rats: Dataset of systemic oxidative stress and inflammation markers. Data in Brief. 2016 6//;7:460-7.

13. Chen W, Su H, Xu Y, Bao T, Zheng X. Protective effect of wild raspberry (Rubus hirsutus Thunb.) extract against acrylamide-induced oxidative damage is potentiated after simulated gastrointestinal digestion. Food Chemistry. 2016 4/1/;196:943-52.

14. Zhao M, Wang P, Zhu Y, Liu X, Hu X, Chen F. Blueberry anthocyanins extract inhibits acrylamide-induced diverse toxicity in mice by preventing oxidative stress and cytochrome P450 2E1 activation. Journal of Functional Foods. 2015 4//;14:95-101.

15. Shadnia S, Azizi E, Hosseini R, Khoei S, Fouladdel S, Pajoumand A, et al. Evaluation of oxidative stress and genotoxicity in organophosphorus insecticide formulators. Human \& experimental toxicology. 2005;24(9):439-45.

16. Hanot-Roy M, Tubeuf E, Guilbert A, Bado-Nilles A, Vigneron P, Trouiller B, et al. Oxidative stress pathways involved in cytotoxicity and genotoxicity of titanium dioxide ( $\mathrm{TiO} 2)$ nanoparticles on cells constitutive of alveolo-capillary barrier in vitro. Toxicology in Vitro. 2016 6//;33:125-35.

17. Javed M, Ahmad I, Usmani N, Ahmad M. Bioaccumulation, oxidative stress and genotoxicity in fish (Channa punctatus) exposed to a thermal power plant effluent. Ecotoxicology and Environmental Safety. 2016 5//;127:163-9.

18. Jin Y, Pan X, Fu Z. Exposure to bifenthrin causes immunotoxicity and oxidative stress in male mice. Environmental toxicology. 2014;29(9):991-9.

19. Mahdavi AM, Mahdavi R, Kolahi S, Zemestani M, Vatankhah A-M. 1-Carnitine supplementation improved clinical status without changing oxidative stress and lipid profile in women with knee osteoarthritis. Nutrition Research. 2015;35(8):707-15.

20. Błasiak J, Gloc E, Woźniak K, Młynarski W, Stolarska M, Skórski T, et al. Genotoxicity of idarubicin and its modulation by vitamins $\mathrm{C}$ and $\mathrm{E}$ and amifostine. Chemico-biological interactions. 2002;140[1]:1-18.

21. Singh M, Kaur P, Sandhir R, Kiran R. Protective effects of vitamin E against atrazineinduced genotoxicity in rats. Mutation Research/Genetic Toxicology and Environmental Mutagenesis. 2008;654(2):145-9.

22. Anderson D, Yu T-W, Phillips B, Schmezer P. The effect of various antioxidants and other modifying agents on oxygen-radical-generated DNA damage in human lymphocytes in the COMET assay. Mutation Research/Fundamental and Molecular Mechanisms of Mutagenesis. 1994;307[1]:261-71.

23. Alzahrani HAS. Protective effect of 1-carnitine against acrylamide-induced DNA damage in somatic and germ cells of mice. Saudi journal of biological sciences. 2011;18[1]:29-36.

24. Kasurka CB, Şekeroğlu ZA, Şekeroğlu V. Evaluation of the genotoxicity and cytotoxicity of fexofenadine in cultured human peripheral blood lymphocytes. Toxicology in Vitro. 2011;25(7):1480-4.

25. Fenech M, Morley AA. Measurement of micronuclei in lymphocytes. Mutation Research/Environmental Mutagenesis and Related Subjects. 1985;147(1-2):29-36.

26. Grover P, Rekhadevi P, Danadevi K, Vuyyuri S, Mahboob M, Rahman M. Genotoxicity evaluation in workers occupationally exposed to lead. International journal of hygiene and environmental health. 2010;213(2):99-106.

27. Halliwell B, Whiteman M. Measuring reactive species and oxidative damage in vivo and in cell culture: how should you do it and what do the results mean? British journal of pharmacology. 2004;142(2):231-55. 
28. Zhang X, Jiang L, Geng C, Yoshimura H, Zhong L. Inhibition of acrylamide genotoxicity in human liver-derived HepG2 cells by the antioxidant hydroxytyrosol. Chemico-biological interactions. 2008;176(2):173-8.

29. Shokrzadeh M, Zamani E, Mehrzad M, Norian Y, Shaki F. Protective effects of propofol against Methamphetamine-induced neurotoxicity. Toxicology International. 2015;22[1]:92.

30. Pedreschi F, Moyano P, Kaack K, Granby K. Color changes and acrylamide formation in fried potato slices. Food Research International. 2005;38[1]:1-9.

31. LoPachin RM. The Changing View of Acrylamide Neurotoxicity. NeuroToxicology. 2004 6//;25(4):617-30.

32. Jiang L, Cao J, An Y, Geng C, Qu S, Jiang L, et al. Genotoxicity of acrylamide in human hepatoma G2 (HepG2) cells. Toxicology in Vitro. 2007;21(8):1486-92.

33. Dearfield KL, Douglas GR, Ehling UH, Moore MM, Sega GA, Brusick DJ. Acrylamide: a review of its genotoxicity and an assessment of heritable genetic risk. Mutation Research/Fundamental and Molecular Mechanisms of Mutagenesis. 1995;330[1]:71-99.

34. Doerge DR, Young JF, McDaniel LP, Twaddle NC, Churchwell MI. Toxicokinetics of acrylamide and glycidamide in Fischer 344 rats. Toxicology and Applied Pharmacology. 2005 11/1/;208(3):199-209.

35. Koyama N, Sakamoto H, Sakuraba M, Koizumi T, Takashima Y, Hayashi M, et al. Genotoxicity of acrylamide and glycidamide in human lymphoblastoid TK6 cells. Mutation Research/Genetic Toxicology and Environmental Mutagenesis. 2006;603(2):151-8.

36. Manjanatha M, Aidoo A, Shelton S, Bishop M, McDaniel L, Doerge D, editors. Evaluation of mutagenicity in big blue (BB) mice administered acrylamide (AA) and glycidamide (GA) in drinking water for 4 weeks. Environmental and Molecular Mutagenesis; 2004: WILEY-LISS DIV JOHN WILEY \& SONS INC, 111 RIVER ST, HOBOKEN, NJ 07030 USA.

37. Abramsson-Zetterberg L. The dose-response relationship at very low doses of acrylamide is linear in the flow cytometer-based mouse micronucleus assay. Mutation Research/Genetic Toxicology and Environmental Mutagenesis. 2003;535(2):215-22.

38. Koyama N, Yasui M, Oda Y, Suzuki S, Satoh T, Suzuki T, et al. Genotoxicity of acrylamide in vitro: Acrylamide is not metabolically activated in standard in vitro systems. Environmental and molecular mutagenesis. 2011;52[1]:11-9.

39. Chen W, Shen Y, Su H, Zheng X. Hispidin derived from Phellinus linteus affords protection against acrylamide-induced oxidative stress in Caco-2 cells. Chemico-Biological Interactions. 2014 8/5/;219:83-9.

40. Valko M, Rhodes C, Moncol J, Izakovic M, Mazur M. Free radicals, metals and antioxidants in oxidative stress-induced cancer. Chemico-biological interactions. 2006;160[1]:1-40.

41. Mailloux RJ, McBride SL, Harper M-E. Unearthing the secrets of mitochondrial ROS and glutathione in bioenergetics. Trends in biochemical sciences. 2013;38(12):592-602.

42. Fatima M, Usmani N, Firdaus F, Zafeer MF, Ahmad S, Akhtar K, et al. In vivo induction of antioxidant response and oxidative stress associated with genotoxicity and histopathological alteration in two commercial fish species due to heavy metals exposure in northern India (Kali) river. Comparative Biochemistry and Physiology Part C: Toxicology \& Pharmacology. 2015;176:17-30.

43. Canbolat EP, Sağsöz N, Noyan V, Yücel A, Kısa Ü. Effects of 1-carnitine on oxidative stress parameters in oophorectomized rats. Alexandria Journal of Medicine. 2016.

44. Kalaiselvi T, Panneerselvam C. Effect of L-carnitine on the status of lipid peroxidation and antioxidants in aging rats. The Journal of Nutritional Biochemistry. 1998;9(10):575-81.

45. Sun R, Yin L, Pu Y. The effects of acetyl-1-carnitine to mouse bone marrow cells against benzene induced mitochondrial dysfunction and oxidative stress. Toxicology Letters. 2016 9/16/;258, Supplement:S242. 